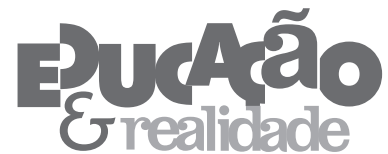

\section{Estudo do \\ Posicionamento dos \\ Alunos na sua Relação com o Sucesso Escolar}

\author{
Ana Maria Morais \\ Isabel Pestana Neves
}

\begin{abstract}
RESUMO - Estudo do Posicionamento dos Alunos na sua Relação com o Sucesso Escolar. O artigo descreve estudos em que o posicionamento foi tomado como uma característica dos contextos da família e da escola que pode ser responsável pelo sucesso escolar. Os estudos, que se baseiam fundamentalmente na teoria de Bernstein, sugerem que o posicionamento é influenciado pelo grupo social dos alunos, sendo o posicionamento mais baixo adquirido por alunos de classes sociais mais baixas e, dentro dessas, pelos alunos que estudam em escolas de contextos sociais desfavorecidos. Sugerem também que um elevado posicionamento influencia favoravelmente o sucesso dos alunos. Contudo, os estudos salientam que o efeito da escola/prática pedagógica pode sobrepor-se ao efeito da classe social.

Palavras-chave: Posicionamento. Contexto de Socialização Primária. Contexto de Socialização Secundária. Sucesso Escolar.
\end{abstract}

ABSTRACT - Study of Students Positioning in Its Relation with School Success. The article reports studies where positioning was taken as a characteristic of family and school contexts that may influence school success. The studies, which are fundamentally based on Bernstein's theory, suggest that positioning is influenced by students' social group, lower positioning being acquired by students from lower social classes and, within them, by those who study in schools located in disadvantaged social contexts. They also suggest that high positioning influences favourably students' success. However, the studies highlight the school/pedagogic practice as a factor that may overcome the effect of social class.

Keywords: Positioning. Primary Socializing Context. Secondary Socializing Context. School Success. 
Estudo do Posicionamento dos Alunos na sua Relação com o Sucesso Escolar

\section{Introdução}

A procura de razões para o (in)sucesso escolar tem sido uma constante em investigação educacional, nomeadamente em estudos de natureza sociológica. No âmbito de uma perspectiva sociológica, a investigação desenvolvida pelo Grupo ESSA (Estudos Sociológicos da Sala de Aula) ${ }^{1}$ tem usado a teoria do discurso pedagógico de Bernstein $(1990 ; 2000)$ como a matriz central para orientar uma conceptualização multifacetada do (in)sucesso dos alunos na escola. As razões para este (in)sucesso têm sido estudadas, considerando as múltiplas características dos contextos de socialização primária (família/comunidade) e dos contextos de socialização secundária (sala de aula/escola), e suas inter-relações (e.g. Morais; Neves, 2003; Pires; Morais; Neves, 2004; Neves; Morais, 2005). De forma a analisar a aprendizagem dos alunos em função das características sociológicas dos contextos da família e da escola, têm sido usados os conceitos, de Bernstein, de orientação específica de codificação e de posicionamento, estudando por exemplo, em que medida a orientação de codificação e o posicionamento adquiridos na família e/ou na escola podem condicionar a aprendizagem de alunos de diferentes grupos sociais e de alunos do mesmo grupo social.

Este artigo pretende descrever estudos do Grupo ESSA em que o posicionamento foi tomado como uma característica diferencial dos contextos da família e da escola que pode ser responsável pelo (in)sucesso escolar. O artigo tem, assim, como objectivos: (1) explicar o significado que tem sido atribuído ao posicionamento, nos estudos até agora realizados, apresentando instrumentos usados para obter e analisar os dados e tornando claro o desenvolvimento da respectiva linguagem externa de descrição; (2) apresentar os resultados dos estudos, salientando a importância de considerar o poscicionamento nas análises da aprendizagem escolar de alunos socialmente diferenciados.

\section{Enquadramento Teórico}

De acordo com Bernstein (1990; 2000), o princípio da divisão social de trabalho, criado pelas relações de classe, determina quer uma posição diferencial dos sujeitos na estrutura hierárquica social, quer relações sociais específicas entre eles.

A figura 1 apresenta esquematicamente as relações que permitem ilustrar o conceito de posicionamento, tal como definido por Bernstein. 
Figura 1 - O Posicionamento, Enquanto Determinado pelas Relações de Classe e Condicionando o Acesso aos Códigos

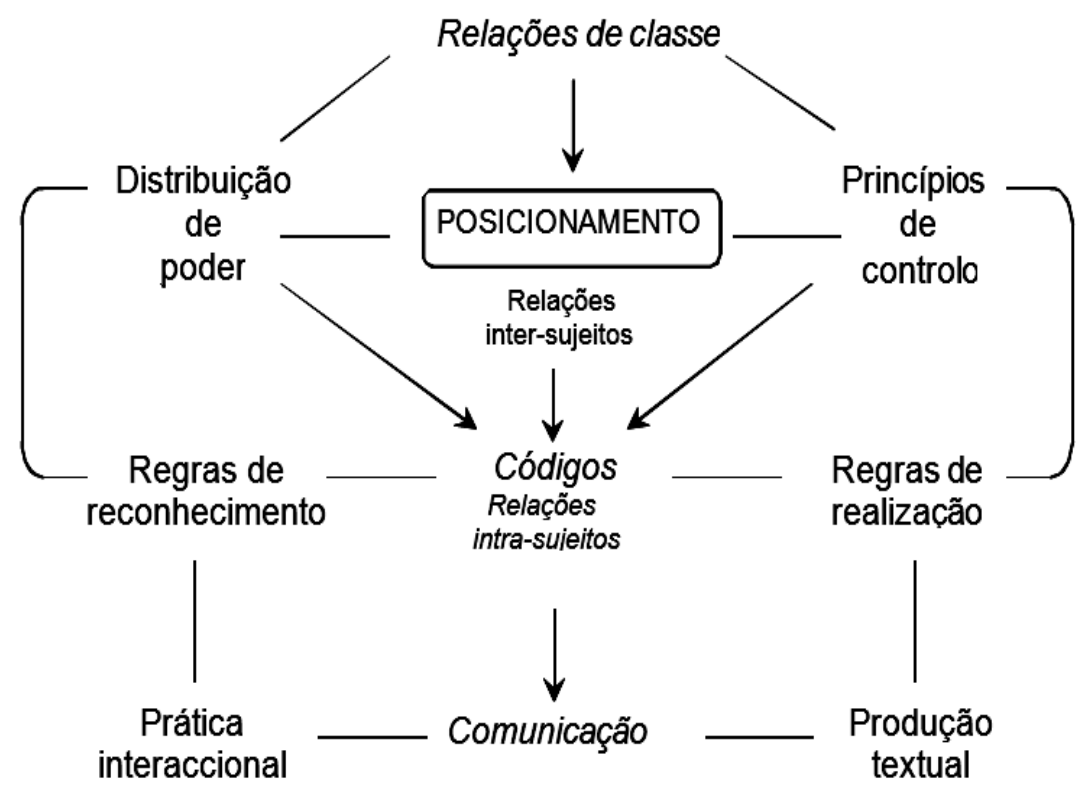

Fonte: Adaptado de Bernstein, 1990.

O posicionamento depende da posição diferencial dos sujeitos na hierarquia criada pelas relações de classe e condiciona o acesso a códigos diferenciais, que são tornados visíveis através da comunicação. Uma distribuição desigual dos sujeitos na estrutura de classes leva-os a aceder a contextos limitados ou a múltiplos contextos e, como consequência, leva-os à aquisição de diferentes orientações de codificação (restritas ou elaboradas) ${ }^{2}$, isto é à aquisição de regras de reconhecimento e de realização para contextos específicos. Estas regras, quando interiorizadas pelo sujeito, leva-o a tomar consciência das relações hierárquicas relativamente a sujeitos de outras categorias sociais e, como tal, a tomar consciência do seu posicionamento em relação a outras categorias. A consciência que os sujeitos adquirem da sua posição no $\mathrm{rang}^{3}$ hierárquico, conjuntamente com o texto que lhes é permitido produzir na sua comunicação com outros agentes sociais, está relacionado com o conceito de posicionamento. Tal como é afirmado por Bernstein (1990): "o posicionamento é usado [...] para referir o estabelecimento de uma relação específica com outros sujeitos e a criação de relações específicas dentro dos sujeitos" (p. 13).

O posicionamento baixo está usualmente associado a sujeitos colocados na base da estrutura social hierárquica e o posicionamento elevado está associado a sujeitos colocados no topo dessa estrutura. 
Estudo do Posicionamento dos Alunos na sua Relação com o Sucesso Escolar

Contudo, o baixo posicionamento, primariamente adquirido pelos sujeitos na estrutura de classes da sociedade pode ser alterado (e, também, a orientação de codificação) através da sua participação activa em agências de resistência, oposição e desafio e também em agências de reprodução cultural. Esta participação pode aumentar o posicionamento dos sujeitos e, ao mesmo tempo, através do acesso a outros contextos e respectivas relações, pode permitir o seu acesso a discursos verticais ${ }^{4}$, o que aponta para a possibilidade de uma relação não linear entre classe social, posicionamento e códigos. De facto, pode acontecer que o posicionamento elevado e a orientação elaborada, adquiridos desta forma, sejam transpostos para o local de trabalho onde o sujeito, embora mantendo a mesma ocupação profissional, se posicione diferentemente nas relações inter-sujeitos, que estão subjacentes à hierarquia do local de trabalho, e possa mesmo desafiar as relações de poder. Pode também acontecer que o sujeito chegue a ser promovido dentro daquela hierarquia. É também possível colocar como hipótese que são os sujeitos que começam por desafiar o seu posicionamento no local de trabalho que estão motivados e interessados em participar naquelas agências. De uma forma ou de outra, o elevado posicionamento (e a orientação de codificação elaborada) adquirido pela classe média ou por elementos específicos da classe trabalhadora será transmitido às crianças no contexto familiar e tal situação constituirá uma vantagem quando ingressam no contexto escolar.

Quando o posicionamento é considerado em relação a qualquer estrutura social (sociedade, local de trabalho, família, escola), é possível dizer que os sujeitos podem estar colocados em várias pirâmides hierárquicas sociais. Assim, por exemplo, se uma criança/aluno for tomado como um agente social, é possível pensar em pirâmides hierárquicas reguladas pelo estatuto de classe social, género, idade e parentesco e, também, pelo aproveitamento académico. Dentro desta perspectiva, tem sentido falar de posicionamento específico quando este se refere a uma pirâmide social específica e de posicionamento global relativo a um dado contexto (família, escola) quando o posicionamento é uma função de vários valores de posicionamentos específicos distintos. Uma mesma criança/aluno pode estar localizada em diversas pirâmides hierárquicas e ocupar posições sociais que diferem de acordo com a pirâmide que está a ser considerada, o que pode ou não originar situações de conflito ${ }^{5}$

De acordo com a distribuição dos sujeitos nas várias pirâmides hierárquicas sociais, derivada de relações de poder e de controlo distintas, os sujeitos são diferencialmente posicionados pelos agentes com os quais interagem - o que pode ser designado por hetero-posicionamento - e, simultaneamente, adquirem a consciência da sua própria posição no rang social hierárquico - auto-posicionamento. Por outras palavras, o hetero-posicionamento de um sujeito (situado num dado contexto) depende do rang onde ele é colocado pelos agentes com os quais interage, enquanto o auto-posicionamento depende do rang onde o próprio

296 Educação \& Realidade, Porto Alegre, v. 38, n. 1, p. 293-318, jan./mar. 2013. Disponível em: <http://www.ufrgs.br/edu_realidade> 
sujeito se coloca, de acordo com a percepção que ele tem das relações de poder e de controlo que caracterizam o contexto de que faz parte. Esta forma de operacionalizar o conceito de posicionamento permite pôr como hipótese que, dependendo da situação, o auto e o hetero-posicionamento podem ou não coincidir. É também possível pôr como hipótese que, em casos onde o auto-posicionamento é mais elevado do que o hetero-posicionamento, ocorram situações de conflito, resistência e oposição no contexto social onde a pirâmide hierárquica específica que regula esse posicionamento ${ }^{6}$ é estabelecida.

Partindo desta teorização, o posicionamento foi tomado nos estudos realizados pelo Grupo ESSA como um atributo sociológico que, reflectindo as relações de poder e de controlo presentes em qualquer estrutura hierárquica (sociedade mais ampla, comunidade, família, escola) se manifesta ao nível do sujeito (cidadão/criança/aluno) através da forma como ele se vê valorizado na sociedade/família/escola (auto-posicionamento). Em termos de investigação empírica, a natureza da estrutura hierárquica (relações de poder) e a forma tomada pelas relações sociais (relações de controlo) nos contextos de socialização primária (família) e de socialização secundária (escola) foram usadas como indicadores que permitem a caracterização do posicionamento da criança/aluno no contexto social onde está colocado e que permitem analisar em que medida tal posicionamento pode constituir uma variável mediadora entre o grupo social (classe social, raça, género) e o sucesso escolar e pode ser influenciado pela prática pedagógica da escola.

A escola e a família, agências cruciais de controlo social, representam estruturas organizacionais em que as relações nelas presentes traduzem realizações do princípio de poder inerente à divisão social de trabalho. Mas, como defende Bernstein, se bem que essas realizações sejam limitadas pelas relações de poder criadas pela estrutura de classe, elas contém a possibilidade de mudança dessas relações, através dos princípios de comunicação que definem o contexto pedagógico.

Qualquer contexto pedagógico é constituído por categorias (sujeitos, discursos, espaços) que se relacionam em termos de poder e de controlo. Bernstein usa os conceitos de classificação e de enquadramento para traduzir, respectivamente, as relações de poder e de controlo. A classificação é forte quando as fronteiras entre as categorias estão bem demarcadas e é evidente uma hierarquia de poder e é fraca quando as fronteiras estão esbatidas e o poder está distribuído. O enquadramento é forte quando o controlo está na posse das categorais de maior estatuto e é fraco quando as categorias de menor estatuto também têm algum controlo na relação pedagógica. Dado que, em qualquer contexto pedagógico na família e na escola, os pais e os professores assumem o estatuto mais elevado, a relação de poder entre sujeitos é, neste caso, assimétrica. Contudo, as relações de controlo podem variar de acordo com o controlo dado na comunicação aos filhos e aos alunos. Em termos instrucionais, o controlo refere-se, por exemplo, à selecção do co- 
Estudo do Posicionamento dos Alunos na sua Relação com o Sucesso Escolar

nhecimento a ser transmitido/adquirido, à sequência e ritmo de aprendizagem e aos critérios de avaliação. Sempre que os pais/professores têm o controlo sobre estes principios o enquadramento é forte e quando os filhos/alunos têm algum controlo sobre estes princípios o enquadramento é fraco. Em termos reguladores, o controlo diz, por exemplo, respeito às regras hierárquicas que regulam as relações sociais de comunicação. Neste caso, o enquadramento é forte quando as relações de comunicação são fechadas e é fraco quando as relações de comunicação são abertas.

De acordo com esta conceptualização, embora os contextos pedagógicos na família e na escola possam reproduzir os princípios de poder criados pela estrutura de classe, eles contêm, através da forma tomada pelas relações de controlo (pais-filhos e professores-alunos), o potencial de mudança daqueles princípios. A concretização desse potencial, podendo alterar o efeito de classe sobre o posicionamento, permitirá o acesso de um maior número de alunos ao discurso vertical da escola e conduzirá, consequentemente, a um alargamento do sucesso escolar. Dado que o posicionamento é um factor condicionante do acesso do aluno ao discurso vertical, ele pode ser considerado um atributo sociológico fundamental na relação conceptual entre a família e a escola. O posicionamento pode, então, representar uma variável adequada e necessária a uma análise empírica da família e da escola segundo métodos de avaliação paralelos.

Embora haja uma vasta investigação (ex. Daniels, 1989; Sadovnik, 1995; Singh, 2001) que usa conceitos importantes da teoria de Bernstein, como os conceitos de orientação de codificação, classificação, enquadramento, discurso pedagógico, recontextualização e muitos outros, os investigadores não se têm mostrado interessados em explorar o conceito de posicionamento. Com essa atitude têm-se privado de utilizar uma ferramenta conceptual com grandes possibilidades para comprender as relações que se estabelecem em diversos contextos educacionais, particularmente ao micro-nível da escola e da família. As autoras deste artigo reconheceram, desde os anos 1990, que o posicionamento, aliado à orientação de codificação, surgia, no âmbito da investigação, como um conceito fundamental da teoria de Bernstein, aos níveis da compreensão e da intervenção. Um dos objectivos do presente artigo consiste em chamar a atenção da comunidade educacional para a importância desse conceito.

\section{Posicionamento do Aluno e Sucesso Escolar: estudos exemplares}

Os estudos sobre a relação entre posicionamento e (in)sucesso escolar têm-se centrado em vários contextos de socialização e, de acordo com a especificidade de cada estudo, têm sido construídos instrumentos (questionários, entrevistas) e modelos destinados a obter e a ana- 
lisar várias dimensões do poscionamento das crianças - na família/ comunidade e na escola e sociedade. Tem-se usado, nos estudos, uma metodologia mista de investigação e, de acordo com esta metodologia, a construção dos modelos e dos instrumentos usados na recolha e análise dos dados tem resultado de uma relação dialéctica entre o teórico e o empírico (Morais; Neves, 2007).

Os instrumentos usados na recolha de dados foram pilotados e os critérios de validade e de fiabilidade foram assegurados através de procedimentos específicos de cada estudo. Por exemplo, as entrevistas foram audio gravadas e transcritas, a pilotagem de alguns questionários incluiu também a sua aplicação aos pais/mães (de forma a analisar o grau de consistência entre as respostas dadas pelos filhos e pelos respectivos pais/mães), foi calculado o coeficiente de correlação entre os itens dos questionários. Em todos os estudos, a análise dos dados foi feita com recurso a métodos estatísticos complementados com procedimentos descritivos.

Os problemas de natureza ética que se poderiam levantar, diferentes consoante a especificidade dos estudos, mas semelhantes por estar em causa investigação com alunos de níveis etários baixos, foram acautelados através do conhecimento claro que foi dado aos pais dos alunos (e aos alunos) do que estava envolvido no estudo em causa, dos respectivos objectivos e do pedido de colaboração e autorização. Em nenhum dos estudos foram encontradas reacções negativas por parte de alunos e pais.

\section{Posicionamento no Contexto de Socialização Primária}

Em estudos centrados no contexto de socialização primária (Neves, 1992; Antunes, 1999), usou-se o posicionamento como um atributo que, reflectindo as relações de poder e de controlo presentes na estrutura hierárquica familiar, se manifesta ao nível do sujeito (criança) através da forma como ela se vê socialmente valorizada na família/comunidade. Dentro desta perspectiva, admite-se que as relações de poder e de comunicação que caracterizam uma dada estrutura familiar reflectem a posição sociológica da família dentro da estrutura de classes e que o posicionamento da criança, enquanto membro de uma dada família, reflecte não só a posição sociológica da família mas também as relações de poder e de comunicação presentes na estrutura familiar. Assim, considerou-se que o posicionamento da criança, decorrente do processo de socialização primária, pode ser analisado segundo duas componentes que, embora interligadas, traduzem formas diferentes de expressão desse posicionamento: (a) o posicionamento enquanto reflexo da forma como a criança posiciona a sua família na hierarquia social criada pela estrutura de classes; e (b) o posicionamento enquanto reflectindo a forma tomada pelas relações sociais que caracterizam a sua estrutura hierárquica familiar.

Educação \& Realidade, Porto Alegre, v. 38, n. 1, p. 293-318, jan./mar. 2013. 
Estudo do Posicionamento dos Alunos na sua Relação com o Sucesso Escolar

Um dos estudos (Neves, 1992) tinha como objectivo analisar a relação entre o posicionamento na família/comunidade e o aproveitamento escolar de crianças socialmente diferenciadas. Considerando, no entanto, que o contexto social da escola pode mediar a relação entre o posicionamento adquirido pela criança no contexto de socialização primária e o seu aproveitamento escolar, o estudo teve igualmente em conta as características sociológicas da prática pedagógica escolar que, em princípio, podem ser responsáveis pela alteração ou pela reprodução do posicionamento diferencial das crianças. Foi assumido que crianças de grupos favorecidos, que tendem a ser socializadas na família através de relações de fraco enquadramento, revelarão elevado posicionamento, enquanto crianças de grupos desfavorecidos, que tendem a ser socializadas através de relações sociais de forte enquadramento, revelarão baixo posicionamento ${ }^{7}$.

A amostra era constituída por 80 crianças socialmente diferenciadas (classe social ${ }^{8}$, raça ${ }^{9}$ e género) dos $5^{\circ}$ e $6^{\circ}$ anos de escolaridade. As crianças faziam parte da população de alunos não repetentes de quatro turmas, com uma composição social heterogénea semelhante que, no decurso dos dois anos de escolaridade, foram submetidas, na disciplina de ciências, a uma de três modalidades distintas de prática pedagógica implementadas pela mesma professora. Uma das práticas caracterizava-se globalmente por classificações e enquadramentos fortes, correspondendo a uma prática de natureza didáctica, centrada no transmissor; outra prática, oposta a esta, caracterizava-se globalmente por classificações e enquadramentos fracos, correspondendo a uma prática de natureza auto-reguladora, centrada no aquisidor; e uma outra prática que, nalgumas características, se assemelhava à primeira e, noutras características, se assemelhava à segunda. Esta última prática apresentava características próximas da prática que, em estudos posteriores, se passou a designar como prática pedagógica mista (e.g. Morais; Neves, 2003).

Para analisar o posicionamento das crianças utilizaram-se dois questionários de escolha múltipla, cada um dos quais apresentado em duas versões que diferiam na sua referência ao pai ou à mãe (Neves; Morais, 1990) e que foram respondidos em situação de entrevista. Um dos questionários continha itens relacionados com a percepção das crianças quanto aos estatutos académico e profissional do pai e da mãe. Os itens foram elaborados em função: (a) das aspirações económicas e educacionais dos filhos, em confronto com a posição académica e económica dos pais (por exemplo, "gostava de ter uma profissão em que ganhasse mais do que o meu pai/mãe”); (b) da imagem que os filhos têm da autoridade do pai/mãe no local de trabalho (por exemplo, "o meu pai/mãe ocupa uma posição importante no local onde trabalha”); (c) da importância que os filhos atribuem à habilitação académica do pai/mãe (por exemplo, "gostava de ter mais estudos do que o meu pai/mãe tem"; (d) do estatuto sócio-económico que os filhos atribuem à profissão do 
pai/mãe (por exemplo, "o meu pai/mãe ganha mais do que os meus professores”). Para cada item foram apresentadas três opções, respectivamente de afirmação ("sim"), de negação ("não") e de dúvida ("não sei"). Às respostas que expressavam uma percepção positiva, foi atribuído o valor 3 e às questões que expressavam uma percepção negativa, o valor 1. A resposta de dúvida, considerada como intermédia, foi valorizada com 2 pontos, baseando-se esta valorização no pressuposto de que uma criança que não sabe, por exemplo, se o pai/mãe ganha pouco (um dos itens incluídos no questionário) não tem a mesma percepção de uma outra criança que, tendo consciência desse facto, posiciona negativamente o pai/mãe. O outro questionário continha itens relacionados com o espaço de comunicação que é dado aos filhos nas suas relações com o pai e com a mãe. Na sua construção teve-se em conta os seguintes parâmetros: (a) liberdade que é dada aos filhos para criticar acções ou intervenções dos seus pais (por exemplo, "quando o teu pai/mãe faz alguma coisa que tu achas mal, tu dizes-lhe”); (b) autonomia que é dada aos filhos quanto a interesses relacionados com o seu dia-a-dia (por exemplo "és tu que escolhes a roupa que vestes quando sais de casa"); (c) iniciativa dos filhos em comunicar com o pai/mãe (por exemplo, "contas ao teu pai/mãe coisas que te acontecem"); (d) interesse do pai/mãe em comunicar com os filhos (por exemplo, "o teu pai/mãe conta-te coisas que se passam no seu local de trabalho"); (e) intervenção do pai/mãe no sentido de enaltecer os actos positivos dos filhos e de castigar os seus actos negativos (por exemplo, "o teu pai/mãe elogia-te, quando fazes coisas certas). Para cada item havia quatro opções - "sempre", "muitas vezes", "poucas vezes" e "nunca" mas, para efeitos de análise, as respostas foram condensadas em duas categorias, valorizadas com 2 ou 1 pontos, consoante representassem, no contexto da questão, relações de comunicação de enquadramento fraco (indicador de posicionamento elevado) ou relações de comunicação de enquadramento forte (indicador de posicionamento baixo).

A partir do somatório dos pontos obtidos na totalidade das respostas dadas em cada um dos questionários, procedeu-se à distribuição das crianças de acordo com uma escala de 4 graus que, em termos gerais, traduzia uma hierarquia de posicionamento ( 1 - muito baixo; 2 - baixo; 3 - médio; 4 - elevado). A relação entre o posicionamento da criança na família/comunidade e outras variáveis do estudo - grupo social (classe social, raça, género), aproveitamento escolar em ciências e prática pedagógica da escola - foi analisada com recurso ao método estatístico de análise de variância, tendo-se utilizado, no tratamento dos dados, uma escala condensada de duas categorias: categoria 1 (resultante da associação dos graus 1 e 2) como traduzindo um posicionamento baixo e categoria 2 (resultante da associação dos graus 3 e 4) como traduzindo um posicionamento elevado. Na interpretação das relações, além dos dados de natureza quantitativa obtidos através das análises de variância, recorreu-se a dados de natureza qualitativa, baseados em análises de tipo descritivo.

Educação \& Realidade, Porto Alegre, v. 38, n. 1, p. 293-318, jan./mar. 2013. 301

Disponível em: <http://www.ufrgs.br/edu_realidade> 
Estudo do Posicionamento dos Alunos na sua Relação com o Sucesso Escolar

Os resultados mostraram existir uma relação significativa entre a classe social (e a raça) e o posicionamento da criança na família/comunidade. São as crianças socialmente mais favorecidas que adquirem, no contexto de socialização primária, um posicionamento mais elevado. Foi também possível constatar que existe uma relação entre o posicionamento e o aproveitamento cognitivo em ciências. As crianças com posicionamento elevado na família/comunidade revelaram, na disciplina de ciências, um nível de aproveitamento cognitivo superior ao nível atingido pelas crianças com posicionamento baixo (quer em relação às competências cognitivas simples, quer em relação às competências cognitivas complexas). A articulação dos resultados obtidos nas diferentes análises sugere a existência da relação "classe social - posicionamento na família/comunidade - aproveitamento cognitivo em ciências", indicando que o posicionamento adquirido pela criança no contexto de socialização primária pode constituir um dos factores sociológicos que explicam a influência da classe social no aproveitamento diferencial dos alunos.

Quando se analisa a influência do contexto escolar naquela relação, os resultados apontam para a possibilidade de práticas pedagógicas específicas esbaterem o efeito do posicionamento (primariamente adquirido na família/comunidade) sobre o aproveitamento em ciências, particularmente no caso das crianças com baixo posicionamento e, de entre estas, das raparigas. Uma prática pedagógica que, simultaneamente, se caracterize por uma explicitação clara do conhecimento científico a ser adquirido (forte enquadramento quanto aos critérios de avaliação) e por relações de comunicação abertas entre professoralunos (enquadramento fraco quanto às regras hierárquicas) parece ter a potencialidade de alterar o posicionamento baixo que as crianças adquirem no contexto de socialização primária, levando a uma alteração positiva no seu aproveitamento em ciências. Tal como estudos mais recentes (e.g. Pires, 2001; Pires; Morais; Neves, 2004) têm revelado, estas características da prática pedagógica são cruciais para o posicionamento e sucesso escolar dos alunos. Eles apontam também para outras características da prática pedagógica (por exemplo, fraco enquadramento quanto ao tempo de aprendizagem) que podem levar as crianças com baixo posicionamento a alcançar sucesso na escola.

O estudo realizado por Antunes e Morais (1993a), que usou a mesma amostra do estudo anteriormente descrito, mas em que o posicionamento das crianças foi analisado em termos do contexto escolar ${ }^{10}$ na sua relação com o grupo social, aproveitamento escolar e prática pedagógica, sugere que o posicionamento na escola depende do grupo social e é um factor determinante para o desempenho dos alunos em competências cognitivas complexas. Sugere também que uma prática pedagógica caracterizada, entre outros aspectos, por relações abertas de comunicação professor-aluno conduz a uma evolução positiva do posicionamento e a uma melhoria no aproveitamento. Estes resulta- 
dos, conjuntamente com os resultados do posicionamento na família, apoiam a ideia de que o baixo posicionamento adquirido na família pode também conduzir a um baixo posicionamento na escola mas que uma prática pedagógica com determinadas características pode mudar o posicionamento e, através desta mudança, levar a uma evolução positiva do aproveitamento dos alunos.

Ambos os estudos analisaram a relação da orientação geral de codificação ${ }^{11}$ das crianças com o posicionamento na família e na escola e também com o aproveitamento escolar. Estas análises mostraram, como seria teoricamente previsível, que a orientação de codificação elaborada tende a estar associada a um elevado posicionamento e que esta associação se verifica em crianças socialmente favorecidas e que são bem sucedidas na escola. Uma orientação de codificação restrita tende a estar associada a um baixo posicionamento e verifica-se em crianças desfavorecidas e com insucesso escolar. Contudo, os resultados também mostraram que a relação "grupo social - posicionamento - código” nem sempre é linear. Por exemplo, crianças socialmente desfavorecidas nem sempre têm baixo posicionamento e orientação de codificação restrita e crianças com baixo posicionamento na família nem sempre possuem orientação restrita e podem, em ambos os casos, ser bem sucedidas na escola. A primeira situação pode ser uma consequência da participação activa dos pais em agências de resistência/ desafio/oposição ou de reprodução cultural e/ou das relações sociais que os pais mantém com sujeitos da classe média, o que pode esbater o efeito de classe social nas relações em análise. Esta hipótese explicativa foi apoiada por estudos de caso realizados com crianças cujos padrões de relação se desviavam do que seria teoricamente expectável (Neves; Morais, 2005). Uma possível explicação para a segunda situação tem a ver com o facto do baixo posicionamento primariamente adquirido na família poder ser alterado na escola como consequência de características específicas da prática pedagógica, como é o caso de relações abertas de comunicação entre professor e alunos e entre alunos de grupos sociais distintos (por exemplo, uma prática pedagógica caracterizada por um fraco enquadramento nas regras hierárquicas ao nível da relação entre sujeitos). Através de relações inter-pessoais, a criança pode adquirir um elevado posicionamento na escola, o que cria condições para a aquisição da orientação de codificação elaborada da escola e, como consequência, para o sucesso escolar.

Num estudo mais recente (Antunes, 1999), também realizado ao nível dos $5^{\circ}$ e $6^{\circ}$ anos de escolaridade, foi analisada a relação entre grupo social (classe social, raça), posicionamento e aproveitamento escolar, em várias disciplinas, de crianças socialmente desfavorecidas, parte das quais pertenciam a grupos de risco. Neste estudo, foi também analisada a relação entre posicionamento e orientação específica de codificação ${ }^{12}$ das crianças para o contexto regulador da escola/sala de aula. Os dados sobre o posicionamento na família e na escola foram

Educação \& Realidade, Porto Alegre, v. 38, n. 1, p. 293-318, jan./mar. 2013. 303

Disponível em: <http://www.ufrgs.br/edu_realidade> 
Estudo do Posicionamento dos Alunos na sua Relação com o Sucesso Escolar

obtidos através de questionários de escolha múltipla contendo itens semelhantes ${ }^{13}$, de forma a permitir estabelecer um paralelismo entre os dados.

As análises mostraram algumas semelhanças entre o posicionamento das crianças face aos pais e o seu posicionamento face aos professores e também entre o seu posicionamento face aos irmãos/ primos $^{14}$ e o posicionamento face aos colegas. Esta semelhança apoia resultados de estudos anteriores realizados na família (Neves, 1992) e na escola (Antunes; Morais, 1993a). Contudo, no caso dos alunos que mostraram, simultaneamente, um elevado grau de resistência à escola e um baixo nível de desempenho (e baixo nível de orientação específica de codificação) no contexto regulador, os resultados evidenciaram relações diferenciais no posicionamento no que respeita aos pares de variáveis equivalentes nos contextos da escola e da família (professores-pais e colegas-irmãos/primos). A descontinuidade entre o posicionamento na família e o posicionamento na escola (maior na escola e menor na família), evidente neste grupo de crianças, consideradas como crianças em risco, pode ser um sinal de que estas crianças são diferencialmente socializadas em cada um dos dois contextos. É possível pensar que as relações de poder e de controlo no contexto da família sejam caracterizadas por valores de classificação e de enquadramento muito fortes e mais fortes do que no contexto da escola.

Embora os resultados apoiem parcialmente estudos anteriores no que concerne a relação entre grupo social e posicionamento na família e na escola, eles mostram que a relação "posicionamento - orientação específica de codificação - aproveitamento escolar" não é sempre linear. De facto, alguns alunos que têm elevado posicionamento na escola revelam não só baixo nível de orientação de codificação (para o contexto regulador) como baixo nível de aproveitamento cognitivo. São alunos que usam o posicionamento como uma forma de desafiar o poder do professor e como um meio de perturbar o funcionamento da escola/sala de aula, e não como uma forma de desenvolver relações que possam conduzir à melhoria do seu desempenho cognitivo. Sugere-se, neste estudo, que o fraco desempenho cognitivo destes alunos pode não estar relacionado com a ausência de orientação de codificação para o contexto instrucional mas com a ausência de orientação de codificação para o contexto regulador e também com a ausência de disposições sócioafectivas ${ }^{15}$ para ambos os contextos.

\section{Posicionamento no Contexto de Socialização Secundária Posicionamento no Contexto Social da Escola}

Este estudo (Miranda; Morais, 1996) dá continuidade a investigação anterior focada no posicionamento do aluno e ensino das ciências e pretende dar resposta a questões semelhantes. Contudo, a questão nova 
e fundamental a que este estudo se dirige está relacionada com o contexto social em que a escola se insere. Como é que o posicionamento dos alunos está relacionado com o contexto social da escola? A expressão contexto social é utilizada em sentido geral, enquanto referindo-se ao tipo de escola e ao local onde ela está situada, partindo-se da ideia de que escolas situadas em meios sócio-económicos e culturais diferentes reproduzem estuturas organizacionais e formas de comunicação diferenciadas que se reflectem na sala de aula.

A amostra era constituída por alunos do $5^{\circ}$ ano de escolaridade que pertenciam a quatro turmas de duas escolas do mesmo distrito uma escola localizada na capital do distrito e outra localizada numa vila desse distrito - e pelas respectivas professoras de ciências, uma de cada escola. A escola situada na capital de distrito tinha uma população socialmente hetrogénea e a outra escola era socialmente homogénea constituída apenas por alunos da classe trabalhadora. O estudo usou uma sub-amostra de crianças (33), seleccionada a partir da amostra global das 4 turmas com base nos seguintes critérios: igual número de alunos da classe média e da classe trabalhadora; igual número de raparigas e de rapazes de cada classe social; igual número de alunos com bom e com mau aproveitamento de cada grupo social.

O posicionamento dos alunos foi determinado a partir dos dados obtidos através de uma entrevista semi-estruturada. Partiu-se do pressuposto que quando o aluno é colocado face a um determinado conhecimento e a uma determinada relação de comunicação, estabelece uma comparação com o conhecimento que possui e com a prática pedagógica que lhe é familiar e coloca-se numa estrutura hierárquica que reflecte a relação que ela estabelece com os outros. Dentro desta perspectiva, usaram-se como indicadores do posicionamento, a percepção que o aluno tem (a) dos conhecimentos adquiridos e (b) das relações de comunicação que se estabelecem em contextos escolares diferenciados em termos de localização da escola.

$\mathrm{Na}$ entrevista, foram usados os testes de avaliação realizados pelos alunos nas duas escolas mas as respostas dos alunos de uma das escolas basearam-se nos testes feitos na outra escola. A primeira questão era a seguinte: "Para que ano de escolaridade pensas que teria sido feito este teste?" Após responderem a esta questão, foi-lhes dito que o teste tinha sido feito para o $5^{\circ}$ ano de escolaridade e foi colocada a segunda questão: "Em qual das seguintes terras - Lisboa, Nisa, Crato, Portalegre, Évora ${ }^{16}$ - teria sido feito o teste?" Com a primeira questão pretendia-se operacionalizar o posicionamento face ao conhecimento escolar (hierarquia do conhecimento dentro da escola) e com a segunda questão pretendia-se operacionalizar o posicionamento face à sociedade (hierarquia das escolas em termos da sua localização). De acordo com o estudo piloto, esperava-se que no caso da primeira questão as respostas se baseassem no grau de dificuldade das questões do teste enquanto no caso da segunda questão as respostas revelariam juízos de valor so- 
bre os colegas e/ou sobre a prática pedagógica de escolas inseridas em meios socioculturais diferentes.

Com base nas respostas dos alunos, foi determinado o seu posicionamento na escola e na sociedade e a relação entre as duas formas de posicionamento. Seguiu-se o estudo da relação entre posicionamento e classe social, género, aproveitamento escolar, orientação específica de codificação para o contexto de avaliação (Morais; Miranda, 1995) ${ }^{17} \mathrm{e}$ contexto social da escola.

De forma a determinar o posicionamento das crianças na escola, definiram-se os seguintes critérios: quando o aluno considera que um teste (elaborado para o seu nível de escolaridade) avalia conhecimentos de um nível de escolaridade superior ao seu, tal indica que ela desvaloriza os conhecimentos que possui; quando considera que o teste avalia conhecimentos de um nível de escolaridade inferior ao seu, isso indica que ela valoriza os seus conhecimentos. Nesta base, criou-se um sistema de categorias e respectiva escala (ver diagrama da Figura 2).

Figura 2 - Posicionamento na Escola - Diagrama da Metodologia Usada na Análise das Respostas dos Alunos

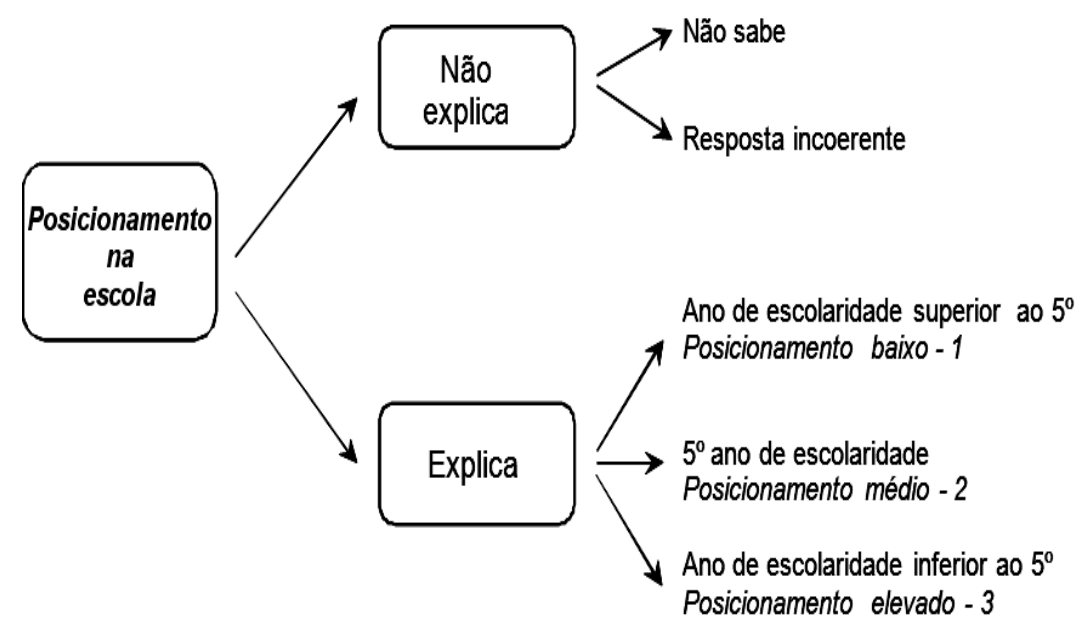

Fonte: Miranda; Morais,1996.

As respostas dos alunos que se transcrevem a seguir exemplificam a forma como foram categorizadas.

Baixo posicionamento (1): Selecciona o $7^{\circ}$ ano - As perguntas são difíceis para o $5^{\circ}$ ano, elas são mais difíceis do que as desta escola.

Posicionamento médio (2): Selecciona o $5^{\circ}$ ano - As perguntas são parecidas com as nossas.

Posicionamento elevado (3): Selecciona anos do $1^{\circ}$ ciclo - 
O teste é mais fácil do que os testes feitos pela nossa professora.

Não explica - Não selecciona - Eu aprendi isso no $5^{\circ}$ ano, não sei como é nos outros anos (Miranda; Morais,1996).

De forma a determinar o posicionamento das crianças na sociedade, pediu-se-lhes que escolhessem a localidade onde o teste teria sido realizado e que explicassem como é que era a aprendizagem das ciências nas escolas dessa localidade. O seu ponto de partida era a dimensão relativa das localidades, ou seja a selecção pressupunha a hierarquia "Lisboa, Évora, Portalegrem, Nisa/Crato" e os argumentos que justificavam a escolha da escola estavam sempre associados a essa relação dimensional.

Foi também, neste caso, criado um sistema de categorias e respectiva escala, tal como está expresso no diagrama da Figura 3.

Figura 3 - Posicionamento na Sociedade - Diagrama da Metodologia Usada da Análise das Respostas das Crianças

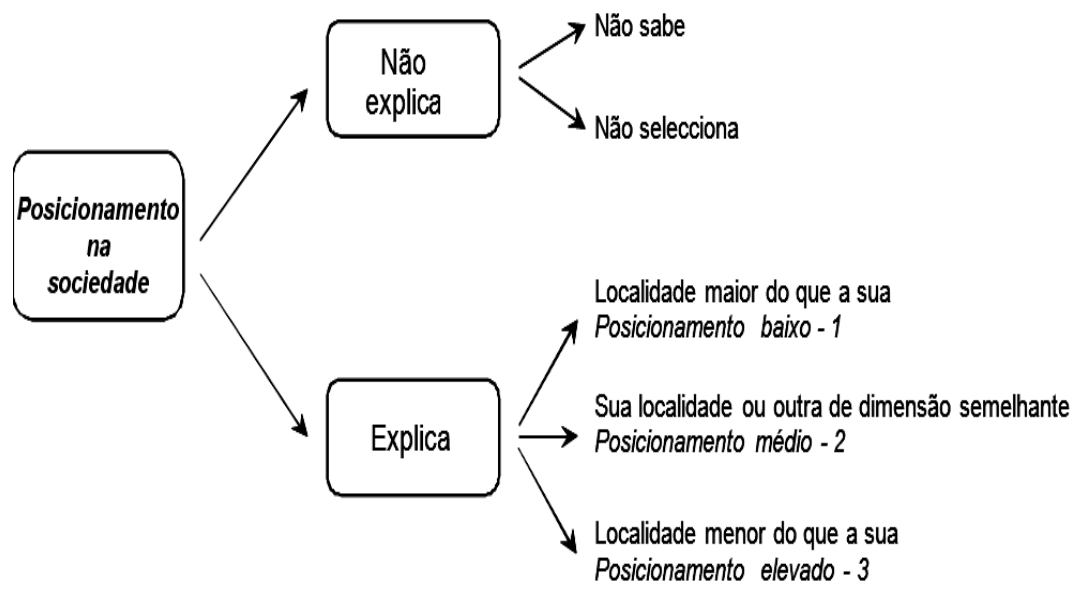

Fonte: Miranda; Morais, 1996.

A análise e comparação das respostas dos alunos não foi sempre linerar mas está fora dos limites deste artigo uma explicitação detalhada dessa análise. De forma a determinar o posicionamento na sociedade, codificaram-se as localidades seleccionadas de acordo com a sua dimensão em relação à localidade onde se situava a escola do aluno. Os exemplos seguintes clarificam os graus de posicionamento considerados, de acordo com os tipos de localidades seleccionadas pelos alunos, e justificações apresentadas.

Baixo posicionamento (1): Selecciona localidades de dimensão superior à da sua escola - Nas terras maiores, os testes são mais difíceis, os professores ensinam melhor.

Educação \& Realidade, Porto Alegre, v. 38, n. 1, p. 293-318, jan./mar. 2013. 
Estudo do Posicionamento dos Alunos na sua Relação com o Sucesso Escolar

Posicionamento médio (2): Selecciona localidades de dimensão semelhante à da sua escola - Os testes devem ser quase iguais aos que a nossa professora faz.

Posicionamento elevado (3): Selecciona localidades de dimensão inferior à da sua escola - Se os alunos sabem menos, os professores têm de pôr perguntas mais fáceis para os alunos compreenderem [...] e às vezes os professores sabem menos e então facilitam.

Não explica - Não selecciona - Não sei como é nas outras terras (Miranda; Morais,1996).

A atribuição de um determinado nível de posicionamento baseou-se no tipo de argumentos que os alunos deram nas suas respostas: (1) associam a dimensão da localidade com a dimensão da escola; (2) associam a dimensão da localidade com o grau de dificuldade dos testes; (3) associam a dimensão da localidade com o nível dos residentes em termos (a) dos saberes, (b) de capacidades intelectuais, (c) de linguagem utilizada; (4) associam a dimensão da localidade com a qualidade do ensino em termos de (a) qualificação dos proessotres, (b) nível de exigência conceptual dos professores.

É interessante notar que, através dos indicadores seleccionados, foi possível compreender a associação que os alunos fazem entre a realidade escolar e o contexto social em que as escolas se inserem. A análise global do conjunto das respostas aponta para uma relação do seguinte tipo: localidades de maior/menor dimensão $\leftrightarrow$ professores que ensinam melhor (mais qualificados e mais exigentes)/professores que ensinam pior (menos qualificados e menos exigentes) $\leftrightarrow$ alunos que aprendem mais (pais que podem dar apoio)/alunos que aprendem menos (pais que não sabem dar apoio) $\leftrightarrow$ testes mais difíceis (itens com maior grau de dificuldade e linguagem mais elaborada)/testes mais fáceis (itens com menor grau de dificuldade e linguagem mais simples). Estes aspectos surgiram com maior ou menor frequência no texto dos alunos.

A relação entre o posicionamento dos alunos e o contexto social onde a escola está inserida é tão marcada que ultrapassa mesmo o efeito de classe por si só, levando a que os alunos da classe trabalhadora da cidade apresentem um posicionamento mais elevado em relação aos alunos da mesma classe do meio rural. A diferença de posicionamento encontrada entre os dois grupos de alunos da classe trabalhadora é possivelmente o reflexo de diferenças no posicionamento dos respectivos pais, transmitido às crianças através dos processos de socialização primária (e.g. Neves, 1992). O contexto social onde a escola está inserida influencia também o nível de exigência conceptual dos professores - a professora da capital de distrito era conceptualmente mais exigente do que a professora da vila desse distrito (Miranda; Morais, 1994). Este resultado reforça resultados de um estudo anterior (e.g. Morais, 1991) em que se verificou que o nível de exigência conceptual do professor aumenta das cidades de província para as grandes cidades. É interessante observar como, através das suas respostas, alguns alunos, revelaram ser capazes de apresentar esta relação. 
Como síntese dos resultados deste estudo, pode dizer-se que o posicionamento dos alunos na escola/sociedade é influenciado pela sua classe social e pelo seu género, tendendo o posicionamento mais baixo a ser adquirido pelos alunos dos estratos sociais mais baixos e, no interior destes, pelas raparigas e ainda pelos alunos que frequentam escolas de meios desfavorecidos. Esse posicionamento está relacionado com a orientação específica de codificação do aluno e influencia o seu sucesso nas competências científicas complexas, isto é, o seu nível de desenvolvimento científico. Desta forma, o estudo confirma, em geral, os resultados dos estudos anteriormente descritos, alargando-os a outras populações e avançando em alguns aspectos.

A relação encontrada noutro estudo, com a mesma amostra, entre a orientação específica de codificação no contexto de avaliação e o aproveitamento dos alunos (Morais; Miranda, 1995), levam a pensar que quer o posicionamento, quer a orientação de codificação dos alunos constituem importantes factores sociológicos associados ao aproveitamento científico, nomeadamente em competências que requerem um elevado nível de abstracção.

\section{Posicionamento no Contexto da Aula de Ciências}

Um outro estudo sobre o posicionamento dos alunos no contexto de socialização secundária centrou-se no $1^{\circ}$ ciclo do ensino básico, no contexto de aprendizagem científica (Pires, 2001). A amostra era constituída por quarto turmas (91 alunos), e respectivas professoras, de quatro escolas localizadas em duas cidades de província. Os dados foram obtidos através de uma entrevista semi-estruturada (Afonso; Pires; Morais; Neves, 1997) aplicada pela investigadora a cada um dos alunos, no início e no fim do ano.

O estudo dá continuidade a estudos anteriores (Neves, 1992; Antunes; Morais, 1993a; Miranda; Morais, 1996), realizados nesta área, que sugeriram relações entre o posicionamento dos alunos na família/comunidade e na escola e a classe social, género, contexto social da escola e da comunidade e aproveitamento escolar. Pretendeu-se ir mais além na análise destas relações, estudando em que medida o posicionamento dos alunos na escola, face aos colegas e face ao professor, é influenciado por práticas pedagógicas com características que têm sido apontadas como favoráveis ao sucesso de todos os alunos. Com esta finalidade, os professores foram envolvidos num processo extensivo de formação, no âmbito de um contexto de investigação-acção. A classe social e o sucesso escolar dos alunos, particularmente em competências cognitivas complexas, e a orientação específica de codificação, no contexto da compreensão de conceitos, constituíram outras variáveis importantes do estudo. Este estudo é parte de uma investigação mais ampla que inclui o estudo, desenvolvido por Pires, Morais e Neves (2004), que sugeriu

Educação \& Realidade, Porto Alegre, v. 38, n. 1, p. 293-318, jan./mar. 2013.

Disponível em: <http://www.ufrgs.br/edu_realidade> 
que uma prática pedagógica mista com determinadas características leva os alunos a alcançar elevados níveis de aprendizagerm científica.

No estudo, o posicionamento dos alunos na escola foi analisado de acordo com duas dimensões inter-relacionadas: o posicionamento dos alunos face aos colegas e o posicionamento dos alunos face ao professor. Para cada uma destas dimensões definiram-se dois indicadores:
1. Posicionamento do aluno em relação aos colegas:
(a) Como é que a criança pensa que os colegas a vêem (questões 1 e 2)
(b) Como é que a criança se vê perante os seus colegas (questões 6, 7 e 8)

\section{Posicionamento do aluno em relação à professora:}
(a) Como é que a criança pensa que a professora a vê (questões 3 e 4)
(b) Como é que a criança se vê perante a professora (ques- tão 5) (Afonso; Pires; Morais; Neves, 1997).

A investigadora começa a entrevista dizendo ao aluno que vão falar sobre a sua escola. Faz então a seguinte introdução: Imagina que na tua escola vai ser realizado um concurso no qual tu vais participar e em que os participantes terão que apresentar um trabalho de grupo com o título "Na minha escola eu aprendo coisas muito importantes". Os prémios serão os seguintes: $1^{\circ}$ prémio - um computador e cinco jogos; $2^{\circ}$ prémio - um computador e um jogo; $3^{\circ}$ prémio - um computador. Nas entrevistas recorreu-se a cartões, cada um dos quais contendo a fotografia (ou o nome) de cada aluno da turma, que foram utilizados pelos alunos (e investigadora) para dar as suas respostas.

A investigadora continua a entrevista, usando as seguintes questões orientadoras:

QUESTÃO 1 - Imagina que eram os alunos que formavam os grupos que iriam participar no concurso. Pensas que os teus colegas te escolheriam para fazer parte do grupo? Porquê?

QUESTÃO 2 - Quais os colegas que pensas que te escolheriam? Porquê?

QUESTÃO 3 - Imagina agora que era a tua professora que formava os grupos de trabalho que iriam participar no concurso. Quais são os grupos que pensas que a tua professora iria formar? Porquê? (Afonso; Pires; Morais; Neves, 1997).

Se o aluno faz grupos homogéneos em termos de aproveitamento, a entrevista continua com a questão 4 . Se o aluno faz grupos heterogéneos, a entevistadora faz três grupos - um grupo com alunos de aproveitamento bom, um grupo com alunos de aproveitamento médio e outro grupo com alunos de aproveitamento fraco - e coloca de seguida a questão 4 . 
QUESTÃO 4 - Em qual destes três grupos, pensas que a tua professora te incluiria? Porquê?

QUESTÃO 5 - Se não concordasses com os grupos que a tua professora tinha feito, dizias-lhe? Porquê?

QUESTÃO 6 - Dos colegas da tua turma quais consideras que tinham grandes possibilidades de ganhar o concurso? Porquê?

QUESTÃO 7 - Dos colegas da tua turma quais consideras que não têm possibilidades de ganhar o concurso? Porquê?

QUESTÃO 8 - Então, e tu, em que grupo te incluirias: no grupo com muitas possibilidades de ganhar ou no grupo sem possibilidades de ganhar? Porquê? (Afonso; Pires; Morais; Neves, 1997).

Para cada um dos quatro indicadores de posicionamento, construiu-se uma escala de três graus: 1- Posicionamento baixo; 2- Posicionamento médio; 3- Posicionamento elevado.

Os exemplos que se seguem correspondem a respostas dadas pelas crianças relacionadas com os respectivos graus de posicionamento:

Questão 1- Posicionamento do aluno em relação aos colegas

Posicionamento baixo - "Raramente me escolhem...talvez porque não gostam de trabalhar comigo...”

Posicionamento médio - "Escolhiam...porque brincamos todos juntos..."

Posicionamento elevado - "Sim, escolhiam-me...porque tenho sempre os trabalhos bem feitos...porque a professora dá-me sempre os parabéns..."

Questão 5 - Posicionamento do aluno em relação à professora

Posicionamento baixo - "Não...deixava-me ficar [no grupo] porque a professora é que manda...deixava-me ficar..." Posicionamento médio - "Dizia...porque eu não queria ficar naquele grupo...porque eu não gostava daquele grupo, de lá estar."

Posicionamento elevado - "Sim, é que alguns [alunos] não são os melhores e ela [a professora] podia não prestar muita atenção e escapava-lhe...é que às vezes a professora também se engana a escolher" (Pires, 2001).

Para cada uma das dimensóes do posicionamento, a soma dos pontos obtidos nas respectivas questões permitiu colocar o aluno na seguinte escala: 1 - posicionamento baixo; 2 - posicionamento médio; 3 - posicionamento elevado.

Os resultados mostraram que a evolução, ao longo do ano, do posicionamento dos alunos em relação aos colegas e à professora, estava relacionada com a prática pedagógica, tendo-se obtido os melhores resultados com uma prática pedagógica mista com determinadas carac- 
Estudo do Posicionamento dos Alunos na sua Relação com o Sucesso Escolar

terísticas ${ }^{18}$. O posicionamento e a sua evolução mostraram-se relacionados com a classe social, apresentando os alunos de classe social mais elevada, em geral, maiores níveis de posicionamento. Contudo, alunos de classe social mais baixa também mostraram uma evolução positiva sempre que a prática pedagógica da professora se apoximou da referida prática pedagógica mista. Também se encontrou uma relação do posicionamento dos alunos com a sua orientação específica de codificação para o contexto da compreensão de conceitos e com o seu sucesso em ciências, particularmente nas competências cognitivas complexas. A posse de regras de reconhecimento e de realização, particularmente de realização activa, conjuntamente com um elevado posicionamento, nomeadamente em relação aos colegas, parece contribuir para o sucesso dos alunos de todos os níveis sociais.

\section{Considerações Finais}

Globalmente, os estudos realizados até ao momento sugerem que, em geral, o posicionamento está relacionado com o grupo social, estando o baixo posicionamento associado a alunos das classes sociais mais baixas e, dentro destes, às raparigas e aos alunos de raça negra e também aos alunos que estudam em escolas de contextos sociais desfavorecidos. Eles também sugerem que, em geral, um posicionamento elevado influencia favoravelmente o sucesso escolar dos alunos. A existência da relação "grupo social - posicionamento na família/comunidade - posicionamento na escola - aproveitamento escolar" apoia a ideia de que o posicionamento adquirido pelo aluno no contexto de socialização primária constitui um dos factores sociológicos que pode explicar a relação entre o grupo social e o aproveitamento diferencial. Contudo, os estudos também salientam a importância do poscicionamento adquirido no contexto de socialização secundária na mudança daquele padrão, sugerindo que o efeito da escola/prática pedagógica pode sobrepôr-se ao efeito da classe social. Os estudos reforçam a ideia, sugerida em estudos anteriores, de que as razões para o (in)sucesso escolar não derivam unicamente das características sociológicas da família, dado que os atributos adquiridos pelo aluno no contexto de socialização primária apenas poderão constituir factores determinantes do seu aproveitamento se as práticas pedagógicas realizadas na escola criarem contextos de interacção professor-aluno e aluno-aluno que não tomem em consideração os atributos diferenciais dos alunos. Os resultados apresentados foram obtidos através de análises quer quantativas quer qualitativas. A sua não discriminação por tipo de análise teve a intenção de não alongar demasiado o texto.

Quando o foco da análise é a relação entre a prática pedagógica e o posicionamento dos alunos na escola (em relação ao professor e aos colegas), os resultados sugerem que um baixo posicionamento, usualmente associado a alunos socialmente desfavorecidas, tende a aumentar quando estas recebem uma prática pedagógica que, em termos 
sociológicos, apresenta as seguintes características: forte classificação entre professor e alunos e também entre o conhecimento académico e o não académico e fraca classificação entre alunos e entre discursos (entre conhecimentos da mesma disciplina); forte enquadramento entre professor e alunos no caso da selecção, sequência e critérios de avaliação e fraco enquadramento no caso da ritmagem; fraco enquadramento ao nível das regras hierárquicas quer nas relações professor -alunos quer nas relações entre alunos. Com esta prática, que corresponde a uma prática pedagógica mista (Pires; Morais; Neves, 2004; Morais; Neves, 2009), todos os alunos beneficiam de uma relação aberta de comunicação com o professor e com os colegas e sentem que as suas opiniões, experiências e ritmo de aprendizagem são tidos em consideração. Simultaneamente, todos os alunos têm igual acesso ao texto que é socialmente valorizado/legitimado pela escola e sociedade (dado que ele é tornado pessoalmente explícito). É então possível pensar que, nestas condições, as fronteiras hierárquicas e as distâncias hierárquicas nas pirâmides sociais, que usualmente caracterizam os contextos de sala de aula, serão esbatidas e, como consequência, os alunos que estão na base dessas pirâmides poderão ascender a posições mais elevadas e, portanto, aumentar o seu posicionamento.

Quando o posicionamento é visto em termos do contexto social onde a escola está inserida, os alunos estabelecem uma correspondência entre a estrutura piramidal da sociedade (neste caso, em termos de regiões) e a estrutura piramidal das escolas e consideram que a posição que a escola ocupa nessa hierarquia determina o processo de ensino/ aprendizagem, uma vez que a uma tal posição correspondem também professores e alunos diferenciados. A hierarquia existente na sociedade, quer por razões sociais (relações de classe), quer por razões de natureza administrativa (localidades mais ou menos importantes) repercute-se, pois, na escola ao nível das concepções e dos comportamentos.

Outro resultado interessante dos estudos é que a relação posicionamento da criança na família/classe social não traduz sempre uma relação de associação entre classe trabalhadora e posicionamento baixo e entre classe média e posicionamento elevado. Crianças de famílias da classe trabalhadora podem ter posicionamento elevado quando os pais são sujeitos activos em agências de desafio/oposição/reprodução cultural e/ou mantêm relações sociais com famílias da classe média e crianças de famílias da classe média podem ter posicionamento baixo quando, por exemplo, os pais criam contextos de comunicação caracterizados por um enquadramento muito forte ao nível das regras hierárquicas (e.g. Neves; Morais, 2005). Dentro da classe trabalhadora, o posicionamento pode também diferir consoante a importância da localidade onde as crianças vivem, sendo o posicionamento mais elevado adquirido por crianças de localidades de maior dimensão.

Os estudos sugerem uma relação positiva entre posicionamento e orientação de codificação, estando os níveis mais elevados de ambos associados a grupos sociais mais elevados e a níveis mais elevados de

Educação \& Realidade, Porto Alegre, v. 38, n. 1, p. 293-318, jan./mar. 2013. 
Estudo do Posicionamento dos Alunos na sua Relação com o Sucesso Escolar

sucesso escolar, particularmente nas competências cognitivas complexas. Contudo, esta relação não é sempre linear. Por exemplo, foi possível encontrar casos de elevado posicionamento na escola associados a alunos socialmente desfavorecidos, com baixos níveis de orientação específica de codificação e de aproveitamento escolar. Esta situação revelou-se específica de um grupo de alunos com resistência activa à escola e que, numa pirâmide hierárquica de alunos pertencentes a classes sociais mais baixas, se vêem (e são vistas pelos outros alunos) como estando no topo, com posições de poder, assumindo o papel de lideres para desenvolver relações sociais conducentes a situações de conflito, resistência e oposição. O elevado posicionamento, consequência do rang que eles ocupam nessa pirâmide, é usado como forma de contestação e não de reprodução das normas institucionais, justificando assim o baixo sucesso na escola associado a este grupo de alunos.

Ao mostrar a importância do posicionamento como factor que pode influenciar o aproveitamento diferencial dos alunos, estes estudos indicam uma direcção para futuras investigações. Se bem que o posicionamento do aluno na família/comunidade e na escola pareça mediar a relação entre a classe social (raça e género) e o aproveitamento escolar, permitindo explicar, em certa medida, a descontinuidade/ continuidade existente entre os contextos de socialização primária e secundária, as interpretações feitas com base nos resultados obtidos não podem ser tomadas como generalizações. Elas suscitam hipóteses explicativas que devem ser consideradas em futuros estudos. $\mathrm{O}$ facto de o conceito de posicionamento ter sido considerado segundo uma perspectiva multifacetada levanta alguns problemas de interpretação mas, ao mesmo tempo, permite a emergência de relações que, de outro modo, não se tornariam evidentes.

Recebido em 15 de junho de 2011 Aprovado em 26 de abril de 2012

\section{Notas}

1 O Grupo ESSA está integrado no Instituto de Educação da Universidade de Lisboa.

2 A orientação de codificação restrita refere-se à orientação para significados dependentes do contexto e a orientação de codificação elaborada refere-se à orientação para significados mais independentes do contexto. O sujeito possui uma orientação de codificação elaborada quando possui regras de reconhecimento e de realização para vários contextos de comunicação, isto é, é capaz de distinguir a especificidade dos contextos (reconhecimento) e também de seleccionar (realização passiva) e produzir (realização activa) os significados apropriados a esses contextos.

3 Este termo é usado por Foucault (1985) para designar o 'locus' onde o sujeito está colocado numa determinada pirâmide social hierárquica. Para Foucault, mais do que a forma como o sujeito é visto pelos outros, o posicionamento é algo muito mais profundo, interno ao sujeito, que traduz a forma como o próprio sujeito se vê na estrutura social.

314 Educação \& Realidade, Porto Alegre, v. 38, n. 1, p. 293-318, jan./mar. 2013. Disponível em: <http://www.ufrgs.br/edu_realidade> 
4 De acordo com Bernstein (1999), o discurso vertical refere-se ao discurso académico, em oposição ao discurso horizontal que se refere ao discurso do senso comum/não académico.

5 Por exemplo, uma criança pode estar colocada numa posição próxima da base da pirâmide hierárquica regulada pelo nível académico (é um bom aluno) e numa posição próxima do topo da pirâmide hierárquica regulada pela classe social (pertence a uma família de classe social elevada) e, neste caso, podem surgir situações de conflito. A situação oposta, em que a criança faz parte de uma família de classe social baixa mas é um bom aluno pode levar a que o seu posicionamento aumente na escola e, mesmo, na familia.

6 Por exemplo, no contexto da sala de aula, um aluno pode revelar atitudes de conflito, quando é vista por outros sujeitos (professor e/ou colegas) como tendo um baixo estatuto e ela própria se vê como tendo um elevado estatuto.

7 Vários estudos centrados no contexto de socialização familiar (e.g. Bernstein; Henderson, 1969; Henderson, 1971; Cook-Gumperz, 1973), associam as estatégias de controlo das mães com a cultura de classe da família e sugerem que essas estatégias reflectem determinados princípios hierárquicos nas relações de comunicação mães-filhos.

8 A classe social foi tomada nos vários estudos como um conceito nominal. A profissão e a habilitação académica do pai e da mãe foram usados como indicadores da classe social e, de acordo com a especificidade e/ou com os objectivos do estudo, usou-se um desses indicadores ou um compósito dos quatro.

9 Todos os alunos de raça negra da amostra pertenciam a famílias cabo-verdianas de estatuto social muito baixo.

10 Neste estudo foram consideradas, em separado, duas dimensões do posicionamento na escola: o poscionamento face ao professor e o posicionamento face aos colegas. Os dados foram obtidos a partir de um questionário de escolha múltipla, com uma escala de Likert de 5 opções, constituído por 15 afirmações, algumas relacionadas com o professor e outras com os colegas (Antunes; Morais, 1990). As respostas foram obtidas em situação de entrevista. Os itens seguintes ilustram afirmações incluídas no questionário: "O meu professor acha que as minhas opiniões são muito importantes"; "Os meus amigos da minha turma são melhores alunos do que eu”. A concordância com a primeira afirmação significaria um elevado posicionamento em relação ao professor e a concordância com a segunda afirmação significaria um baixo posicionamento em relação aos colegas.

11 A orientação de codificação foi determinada, neste estudo, através de questionários respondidos em situação de entrevista (Fontinhas; Morais, 1992).

12 A orientação específica de codificação refere-se à orientação para contextos específicos.

13 Ambos os questionários eram questionários de escolha múltipla, com uma escala de Likert de 5 opções, contendo 28 afirmações (Antunes; Morais, 1993b). Os questionários eram equivalentes no sentido em que as afirmações relacionadas com o professor e com os colegas eram semelhantes às afirmações relacionadas com os pais/mães e com os irmãos/primos. As seguintes afirmações são exemplos de itens que ilustram essa semelhança: "Na minha turma acho que sou o/a 'maior"'/"Dos meus irmãos/primos, eu é que sou o/a 'maior'”;"Os meus colegas têm coisas (carro, roupas giras, moram em casas bonitas, etc.) que eu gostava de ter"/"Os meus irmãos/primos têm coisas mais giras do que eu (roupas, brinquedos, etc.)";"Quando não concordo com o que

Educação \& Realidade, Porto Alegre, v. 38, n. 1, p. 293-318, jan./mar. 2013 
Estudo do Posicionamento dos Alunos na sua Relação com o Sucesso Escolar

os meus professores acham, digo-lhes”/“Quando não concordo com aquilo que os meus pais acham, digo-lhes"; "Os meus professores acham que aquilo que eu digo é muito importante"/“Os meus pais dizem bem daquilo que eu faço (na escola, em casa)"

14 Nas famílias cabo-verdianas, os primos têm um estatuto familiar semelhante ao dos irmãos.

15 As disposições sócio-afectivas dizem respeito a valores, interesse, motivação.

16 Todas as cidades são parte da região onde as crianças viviam, com excepção de Lisboa

17 A orientação específica de codificação para o contexto de avaliação foi investigada no mesmo estudo mais amplo. Analisou-se em que medida os alunos compreendem os critérios de avaliação dos professores, mais especificamente os critérios e procedimentos que os professores usam na correcção das respostas aos testes. Foi encontrada uma nítida relação entre a aquisição, pelos alunos, de regras de reconhecimento e de realização e a explicitação pelo professor dos critérios de classificação, a classe social, o contexto social da escola, e o aproveitamento em ciências, particularmente nas competências cognitivas complexas.

18 A prática pedagógica mista foi entendida, neste estudo, como uma prática caracterizada por classificações e enquadramentos fortes ou fracos de acordo com características específicas (Pires; Morais; Neves, 2004; Morais; Neves, 2009).

\section{Referências}

AFONSO, Margarida; PIRES, Delmina; MORAIS, Ana Maria; NEVES, Isabel Pestana. Posicionamento na Escola: guião de entrevista a alunos do $1^{\circ}$ Ciclo do Ensino Básico. 1997. - Materiais de Investigação: instrumento 1.9. Disponível em: <http://essa.ie.ul.pt/ficheiros/instrumentos/portugues/1_ensino_aprendizagem_questionarios_entrevistas/1.9.posicionamento_dos_alunos_na_ escola/1.9.3.pdf>. Acesso em: 01 abr. 2011.

ANTUNES, Helena. Contexto Regulador e Ensino das Ciências: um estudo com crianças dos estratos sociais mais baixos. 1999. Tese (Doutorado em Educação) - Faculdade de Ciências da Universidade de Lisboa, Lisboa, 1999.

ANTUNES, Helena; MORAIS, Ana M. Posicionamento na Escola, em Relação aos Colegas e Professores: questionário a alunos do $2^{\circ}$ Ciclo do Ensino Básico. 1990. - Materiais de Investigação: instrumento 1.9.1. Disponível em: <http://essa. ie.ul.pt/ficheiros/instrumentos/portugues/1_ensino_aprendizagem_questionarios_entrevistas/1.9.posicionamento_dos_alunos_na_escola/1.9.1.pdf >. Acesso em: 01 abr. 2011.

ANTUNES, Helena; MORAIS, Ana Maria. Influência da Socialização Primária e Secundária na Relação entre o Posicionamento e o Aproveitamento na Escola. Revista de Educação, Lisboa, Universidade de Lisboa, v. III, n. 2, p. 59-75, 1993a.

ANTUNES, Helena; MORAIS, Ana Maria. Posicionamento na Família: questionário a alunos do $2^{\text {o }}$ Ciclo do Ensino Básico. 1993b. - Materiais de investigação: Instrumento 1.8.5. Disponível em: <http:// essa.ie.ul.pt/ficheiros/instrumentos/portugues/1_ensino_aprendizagem_questionarios_entrevistas/1.8.posicionamento_dos_alunos_na_ familiacomunidade/1.8.5.pdf $>$. Acesso em: 01 abr. 2011.

ANTUNES, Helena; MORAIS, Ana M. Posicionamento na Escola: questionário a alunos do $2^{\circ}$ Ciclo do Ensino Básico. 1993c. - Materiais de in- 
vestigação: Instrumento 1.9.2. Disponível em: <http://essa.ie.ul.pt/ ficheiros/instrumentos/portugues/1_ensino_aprendizagem_questionarios_ entrevistas/1.9.posicionamento_dos_alunos_na_escola/1.9.2.pdf>. Acesso em: 01 abr. 2011.

BERNSTEIN, Basil. Class, Codes and Control, vol. IV: the structuring of pedagogic discourse. Londres: Routledge, 1990.

BERNSTEIN, Basil. Vertical and Horizontal Discourse: an essay. British Journal of Sociology of Education, v. 20, n. 2, p. 157-173, 1999.

BERNSTEIN, Basil. Pedagogy, Symbolic Control and Identity: theory, research, critique. Londres: Rowman \& Littlefield, 2000.

DANIELS, Harry. Visual Displays as Tacit Relays of the Structure of Pedagogic Practice. British Journal of Sociology of Education, v. 10, n. 2, p. 123-140, 1989.

FONTINHAS, Fernanda; MORAIS, Ana Maria. Orientação Geral de Codificação dos Alunos: questionário. 1992. - Materiais de Investigação: instrumento 1.3.3. Disponível em: <http://essa.ie.ul.pt/ficheiros/instrumentos/portugues/1_ensino_aprendizagem_questionarios_entrevistas/1.3.orientacao_geral_de_codificacao_alunos_e_pais/1.3.3.pdf>. Acesso em: 01 abr. 2011.

FOCAULT, Michael. Surveiller et Punir. Mayenne: Gallimard, 1985.

MIRANDA, Clementina; MORAIS, Ana Maira. O Contexto Social na Relação entre a Exigência Conceptual dos Professores e o Desenvolvimento Científico dos Alunos. Aprender, v. 17, p. 55-70, 1994.

MIRANDA, Clementina; MORAIS, Ana Maria. O Posicionamento dos Alunos na Escola e na Sociedade - Influência dos Contextos Sociais da Escola e da Família. Revista de Educação, Lisboa, Universidade de Lisboa, v. 6, n. 1, p. 89-99, 1996.

MORAIS, Ana Maria. Influência do Nível de Exigência Conceptual dos Professores no Sucesso dos Alunos em Ciências: um estudo sociológico. Revista de Educação, Lisboa, Universidade de Lisboa, v. 2, n. 1, p. 62-80, 1991.

MORAIS, Ana Maria; MIRANDA, Clementina. O Contexto de Avaliação em Ciências: estudo da influência de factores sociológicos. Revista Portuguesa de Educação, Braga, Universidade do Minho, v. 8, n. 2, p. 37-67, 1995.

MORAIS, Ana Maria; NEVES, Isabel Pestana. Processos de Intervenção e Análise em Contextos Pedagógicos. Educação, Sociedade \& Culturas, Porto, Universiade do Porto, n. 19, p. 49-87, 2003.

MORAIS, Ana Maria; NEVES, Isabel Pestana. Fazer Investigação Usando uma Abordagem Metodológica Mista. Revista Portuguesa de Educação, Braga, Universidade do Minho, n. 20, n. 2, p. 75-104, 2007.

MORAIS, Ana Maria; NEVES, Isabel Pestana. Textos e Contextos Educativos que Promovem Aprendizagem: optimização de um modelo de prática pedagógica. Revista Portuguesa de Educação, Braga, Universidade do Minho, v. 22, n. 1, p. 05-28, 2009.

NEVES, Isabel Pestana. O Posicionamento da Criança na Família/Comunidade: influência no aproveitamento escolar. Revista de Educação, Lisboa, Universidade de Lisboa, v. 2, n. 2, p. 35-53, 1992.

NEVES, Isabel Pestana; MORAIS, Ana Maria. Posicionamento na Comunidade: questionário a alunos do $2^{\circ}$ Ciclo do Ensino Básico -1. 1990a. Materiais de Investigação: instrumento 1.8.1. Disponível em: <http:// essa.ie.ul.pt/ficheiros/instrumentos/portugues/1_ensino_aprendizagem_questionarios_entrevistas/1.8.posicionamento_dos_alunos_na_ familiacomunidade/1.8.1.pdf>. Acesso em: 02 abr. 2011.

Educação \& Realidade, Porto Alegre, v. 38, n. 1, p. 293-318, jan./mar. 2013 
Estudo do Posicionamento dos Alunos na sua Relação com o Sucesso Escolar

NEVES, Isabel Pestana; MORAIS, Ana Maria. Posicionamento na Comunidade: questionário a alunos do $2^{\circ}$ Ciclo do Ensino Básico -2. 1990b. Materiais de Investigação: instrumento 1.8.2. Disponível em: <http:// essa.ie.ul.pt/ficheiros/instrumentos/portugues/1_ensino_aprendizagem_questionarios_entrevistas/1.8.posicionamento_dos_alunos_na_ familiacomunidade/1.8.2.pdf >. Acesso em: 02 abr. 2011.

NEVES, Isabel Pestana; MORAIS, Ana Maria. Posicionamento na Família em Relação ao Pai: questionário a alunos do $2^{\circ}$ Ciclo do Ensino Básico. 1990c. - Materiais de investigação: instrumento 1.8.3. Disponível em: <http://essa.ie.ul.pt/ficheiros/instrumentos/portugues/1_ensino_aprendizagem_questionarios_entrevistas/1.8.posicionamento_dos_alunos_na_ familiacomunidade/1.8.3.pdf >Acesso em: 02 abr. 2011.

NEVES, Isabel Pestana; MORAIS, Ana Maria. Posicionamento na Família em Relação à Mãe: questionário a alunos do $2^{\circ}$ Ciclo do Ensino Básico. 1990d. Materiais de Investigação: instrumento 1.8.4. Disponível em: <http://essa.ie.ul.pt/ficheiros/instrumentos/portugues/1_ensino_aprendizagem_questionarios_entrevistas/1.8.posicionamento_dos_alunos_na_ familiacomunidade/1.8.4.pdf >. Acesso em: 03 abr. 2011.

NEVES, Isabel Pestana; MORAIS, Ana Maria. Pedagogic Practices in the Family Socialising Context and Children's School Achievement. British Journal of Sociology of Education, v. 26, n. 1, p. 121-137, 2005.

PIRES, Delmina. Práticas Pedagógicas Inovadoras em Educação Científica Estudo no $1^{\circ}$ ciclo do ensino básico. Tese (Doutorado em Educação) - Faculdade de Ciências da Universidade de Lisboa, Lisboa, 2001.

PIRES, Delmina; MORAIS, Ana Maria; NEVES, Isabel Pestana. Desenvolvimento Científico nos Primeiros Anos de Escolaridade: estudo de características sociológicas específicas da prática pedagógica. Revista de Educação, Lisboa, Universidade de Lisboa, v. 12, n. 2, p. 119-132, 2004.

SADOVNIK, Alan (Org.). Knowledge and Pedagogy: the sociology of Bernstein. Londres: Ablex Publishing, 1995.

SINGH, Parlo. Pedagogic Discourses and Student Resistance in Australian Secondary Schools. In: MORAIS, Ana Maria; NEVES, Isabel Pestana; DAVIES, Brian; DANIELS, Harry (Org.). Towards a Sociology of Pedagogy: the contribution of Basil Bernstein to research (Cap. 10). Nova Iorque: Peter Lang, 2001. P. 251-285.

Ana Maria Morais é professora jubilada e investigadora do Instituto de Educação da Universidade de Lisboa, em Lisboa, Portugal. Áreas de trabalho: Ensino das Ciências e Sociologia da Educação.

E-mail: ammorais@ie.ul.pt

Isabel Pestana Neves é professora reformada e investigadora do Instituto de Educação da Universidade de Lisboa, em Lisboa, Portugal. Áreas de trabalho: Ensino das Ciências e Sociologia da Educação.

E-mail: imneves@ie.ul.pt 